Doi: 10.22201/cimsur.18704115e.2021.v16.537

Revista Pueblos y fronteras digital • ARTÍCULO DE INVESTIGACIÓN

Volumen $16 \cdot 2021 \bullet \mathrm{e}-537$

ISSN $1870-4115$

\title{
Justicia restaurativa para la población yaqui de la frontera entre México y Estados Unidos:
} yaquis del río y yaquis del sur de California

\section{Restorative Justice for the Yaqui Population on the Border between Mexico and the United States: The Yaquis Living along the River and the Yaquis Living in Southern California}

\author{
Aracely Rivera Cohen \\ https://orcid.org/0000-0003-2372-950X \\ Universidad de Arizona, Estados Unidos de América/Universidad de Sonora-Conacyt, México \\ ariveracohen@email.arizona.edu
}

Elia Castro Peralta https://orcid.org/0000-0002-7268-2042

Universidad de Sonora-Conacyt, México eliacastro@email.arizona.edu

Resumen

En este trabajo se presenta el modelo teórico de la justicia restaurativa para el caso de las comunidades yaquis o yoeme del río y del sur de California y se analiza la relación de esta comunidad étnica con sus pares en México y Estados Unidos de América (EUA) en torno a las reivindicaciones de justicia restaurativa. El estudio se llevó a cabo desde una perspectiva que revela la cooperación entre yaquis que viven en México y EUA con respecto a la defensa de los derechos sobre sus tierras, territorios y otros recursos naturales. Asimismo, se abordaron las dificultades legales que estos enfrentan debido a que están en países distintos. Se revisaron las estrategias que utilizan en ambos lados de la frontera para acceder a sus recursos sagrados tales como la tierra, el agua y la cultura. Los hallazgos identificados incluyen el análisis de instrumentos internacionales, nacionales y locales que avalan la justicia restaurativa para la población indígena. Se concluye que, por medio de la justicia restaurativa, y en la medida en que los Estados involucrados acaten las recomendaciones emitidas por organismos internacionales, nacionales y tradicionales, podrán repararse las violaciones a derechos humanos y colectivos pertenecientes a los yaquis.

Palabras clave: luturia, justicia de sanación, prácticas trasnacionales

\section{Abstract}

This paper presents a theoretical model of restorative justice for the case of the Yaquis or Yoeme communities living along the River and those in Southern California. It analyzes the relationship that this ethnic community has with its peers on both sides of the border regarding a claim for restorative justice. The analysis is based on a perspective that reveals the cooperation existing between the Yaquis living in Mexico and those in the United States of America (USA) regarding a defense of their rights to their lands, territories, and other natural resources. It also addresses the legal difficulties they face given that they live in two different countries. Throughout the paper, the reader is presented with the strategies used by the Yaquis living on both sides of the border in order to gain access to their sacred resources such as land, water, and culture. The findings presented in this paper include an analysis of the international, national, and local instruments that endorse 
restorative justice for indigenous peoples. The paper concludes that provided that the States involved adhere to the recommendations issued by international, national, and traditional bodies, restorative justice will ensure reparations for the violations to the human and collective rights to which the Yaquis are entitled.

Key words: Luturia, healing justice, transnational practices

Recibido: 12/10/2020

Aceptado: 05/04/2021

Publicado: 13/12/2021

\section{Introducción}

as violaciones a los derechos humanos y colectivos que ha enfrentado la población yaqui — autonombrada yoeme - incluyen despojo de su territorio (Centro Mexicano de Derecho Ambiental, 2012; Grageda y Molina, 2013; Moreno, 2014; Rivera y Grageda, 2017), despojo y contaminación de las aguas del río Yaqui (Gomez-Rubio et al., 2011; Meza, Kopplin, Burgess y Gandolfi, 2008; Meza et al., 2012; Padilla y Moctezuma, 2017; Radonic, 2015), falta de consulta indígena (Alto Comisionado de las Naciones Unidas, 2016; Organización de las Naciones Unidas-Derechos Humanos, 2018; Stavenhagen, 2003), migración forzada (Rivera, 2020; Schulze, 2018; Vega, 2018) y deportaciones masivas (Padilla, 1995; 2011), entre otras. La justicia restaurativa, cuyo marco teórico busca sanar y remediar daños ocasionados por injusticias directas, sistémicas o históricas (Zehr, 2015), abona (al menos teóricamente) a la reivindicación de lo derechos de la población yaqui. La relevancia del estudio radica en la innovación temática, pues al considerar la expansión de los y las yaquis hacia el sur de California amplía el conocimiento sobre sus prácticas trasnacionales y su justicia.

Las preguntas de investigación que busca responder este trabajo son: ¿qué elementos del modelo de la justicia restaurativa se pueden aplicar al caso yoeme? y ¿cómo opera la relación entre las comunidades del río y las del sur de California con respecto a la justicia restaurativa?

Cabe aclarar que nos referimos a la población de yaquis que habita en los ocho pueblos del territorio yoeme ubicados a lo largo del río Yaqui; para los del sur de California, formalmente establecidos en el condado de Riverside, se requiere poner énfasis en la migración transfronteriza que alude a las prácticas étnicas trasnacionales de las comunidades yaquis con sus pares en territorio yoeme, tanto en México como en EUA. Estas prácticas han contribuido a su supervivencia y resistencia, en el entendido de que son los reclamos de justicia y la consolidación 
de un grupo indígena trasnacional perteneciente a ambos lados de la frontera de México y EUA. Estos lazos étnicos están asociados a su luturia (conocimiento ancestral yaqui), a su cultura, además de a la defensa del territorio y del agua del río (Leza, 2015, 2018; Rivera, 2020; Schulze, 2018; Vega, 2018). En este artículo la división marcada entre yaquis del río y yaquis del sur de California es meramente analítica; los dos grupos se consideran parte de la misma comunidad étnica.

Se realizó una revisión documental y etnográfica que apunta a una justicia restaurativa para la población yaqui; cabe mencionar que esta metodología ha sido utilizada para casos similares. Podemos mencionar a Sawatsky (2009; 2018), quien aborda el tema de la justicia restaurativa inclinada a la sanación al presentar tres casos: Hollow Water, lona Community y Plum Village; otro estudio explora las políticas indigenistas de restauración en la Argentina kirchnerista (Soria, 2019:205); otra investigación expone la reparación simbólica, el trauma y la victimización que significa la respuesta del Estado chileno a las violaciones de derechos humanos, es decir, las torturas y desapariciones ejecutadas durante la dictadura militar de Pinochet (Bustamante y Carreño, 2020). Para el caso yaqui del río y Arizona, Vega (2018) analiza las reivindicaciones por la justicia indígena sobre la lucha étnica trasnacional. Otras publicaciones abonan al análisis de la justicia restaurativa debido a que permite ver la continuidad y el cambio entre los yaquis del río y los del sur de California (Gouy-Gilbert, 2015; Grageda y Molina, 2013; Lerma, 2014, 2015; Olavarría, 2003; Padilla, 1995; 2011; Padilla, Trejo y Donjuan, 2012; Padilla y Moctezuma, 2017; Radonic, 2015; Rivera, 2020). En cuanto a la historia de la lucha por el agua en territorio yaqui, se puede consultar a Padilla y Moctezuma (2017). Sobre los derechos del agua y la violencia ambiental se puede examinar a Radonic (2015). En cuanto a la resistencia yaqui en contra de proyecto de desarrollo hídrico y la autonomía entre yaquis con respecto a otros proyectos de desarrollo se puede consultar a Lerma (2014; 2015). No es la intención exponer detalladamente la historia yaqui; sin embargo, es importante reconocer a varios autores y autoras que han investigado y escrito sobre el tema que aquí nos interesa (Erickson, 2008; Figueroa, 1985; 1993; 1994; Gouy-Gilbert, 2015; Lerma, 2015; Moctezuma, 2001; Olavarría, 2003; Padilla y Reyes, 2015; Padilla et al., 2012; Spicer, 1940b; 1958; 1980).

En este texto se busca describir la relación que tienen los miembros de la Yaqui Nation of Southern California (YNSC, por sus siglas en inglés) con la población del río Yaqui en lo referente a la justicia restaurativa. Primero se presenta un panorama general sobre la justicia restaurativa, es decir, su encuadre teórico e impor- 
tancia; en segundo lugar se destaca la situación de los yaquis en su territorio y en México, así como en California, EUA; después se aborda la justicia restaurativa para ambos grupos étnicos por medio de instrumentos internacionales, nacionales y consuetudinarios que dan sustento a la lucha indígena emprendida históricamente. El análisis de los instrumentos incluye la Declaración de las Naciones Unidas sobre los derechos de los pueblos indígenas (la Declaración), el Convenio núm. 169 de la Organización Internacional del Trabajo (OIT), la Constitución Política de los Estados Unidos Mexicanos, el Decreto de Cárdenas, las medidas cautelares emitidas por la Comisión Interamericana de Derechos Humanos $(\mathrm{CIDH})$, la Propuesta de Iniciativa de Ley Indígena, el Plan de Justicia Yaqui y documentos emitidos por la Organización de las Naciones Unidas (ONU) respecto a la violación sistémica de los derechos humanos y colectivos hacia esta población étnica. Posteriormente se mencionan las estrategias que está desarrollando la YNSC y se hace énfasis en su estrecha relación con sus pares en territorio indígena y mexicano. Y se concluye con recomendaciones que abonan a la justicia restaurativa para yaquis del río y del sur de California.

\section{Revisitando la justicia restaurativa}

La justicia restaurativa identifica y aborda colectivamente las injusticias, necesidades y obligaciones que surgen como resultado de delitos o daños encaminados a la violación de derechos humanos; asimismo, incluye el sanar y remediar daños sufridos por las partes involucradas. Colectivamente se identifican y se plantean soluciones a necesidades, daños y obligaciones con la intención de hacer justicia hasta donde sea posible; la ofensa por un problema que no ha sido restaurado puede ser directa, sistémica o histórica. Este tipo de justicia está dirigida a pueblos que han sido oprimidos y que buscan una justicia transformadora (Zehr, 2015:48). Los principios de la justicia restaurativa consisten en enfatizar los daños infligidos y las necesidades a subsanar, resarcir los daños a manera de sanarlos, trabajar colaborativamente con todas las partes involucradas (incluyendo víctimas, infractores y comunidades) y reparar las malas prácticas de una manera que sea relevante para la población aludida (Zehr, 2015).

Por otra parte, la justicia restaurativa se considera una práctica de sanación que contempla a la justicia decolonial como un concepto dirigido a sanar. En este

\footnotetext{
${ }^{1}$ Plan de justicia yaqui: territorio, agua y desarrollo. Acuerdo presidencial/INPI y Autoridades Tradicionales de la Tribu Yaqui, 12 de diciembre 2019, Pótam, pueblo Yaqui, Sonora, México.
}

\section{4}

Revista Pueblos y fronteras digital • volumen 16 • 2021, pp. 1-30 •ISSN 1870-4115 
marco, Sawatsky $(2009 ;$ 2018) afirma que las mismas comunidades afectadas son las encargadas de su propio bienestar al confrontar las injusticias con sabiduría, respeto y amor, y define la justicia de sanación como un paradigma o imaginario colectivo encaminado a la supervivencia, que transforma daños, fomenta condiciones de vida digna y contempla a las comunidades, las estructuras sociales, el medio ambiente y el mundo espiritual. Asimismo, este tipo de justicia ha sido ampliamente explorado desde la perspectiva indígena por otros y otras académicas (Guest, 2005; McCaslin, 2005; Point, 2005; Valandra, 2005).

En el contexto indígena, la justicia restaurativa está estrechamente vinculada al derecho consuetudinario, a la soberanía, al derecho a la autodeterminación y a la decolonización (McCaslin, 2005; Point, 2005; Valandra, 2005). Cabe mencionar que el racismo sistémico es el daño que las poblaciones indígenas han sufrido durante siglos; por lo tanto, las necesidades por cubrir incluyen la reparación de las violaciones de derechos humanos y colectivos que han sido infligidas históricamente desde la colonización hasta nuestros días. Para lograrlo se requiere la participación de las mismas poblaciones, así como del Estado-nación al que se asocian; también debe procurarse la inclusión de las demás comunidades involucradas. Por último, se requiere utilizar una óptica indígena para la reparación de los daños.

La justicia que la comunidad yaqui ha estado demandando es de un tipo que busca reparar la oleada de violaciones de derechos humanos y colectivos que han enfrentado; que restaure los daños que han traído tantos años de injusticias $y$, en este sentido, que sea transformativa y con enfoque de sanación.

Desde la perspectiva de la justicia restaurativa se aboga por incluir el punto de vista del derecho consuetudinario; por lo tanto, es fundamental contemplar la luturia (conocimiento ancestral yaqui) como un elemento indispensable para el acceso a la justicia que respalda el fortalecimiento de las relaciones trasnacionales entre pares en ambos lados de la frontera México-EUA donde habitan los yaquis del río y del sur de California. Para el caso de la YNSC, el tipo de justicia que buscan es una que les permita sanar los daños y traumas históricos heredados de sus ancestros y perpetuados por colonizadores, gobiernos y compañías trasnacionales. Su estrategia se desarrolla por medio del fortalecimiento de los lazos políticos y culturales establecidos históricamente con sus pares en México y EUA. Tanto para yaquis del río como para quienes habitan al sur de California es tiempo de remediar la opresión sistémica y el trauma histórico que la acompaña. Por consiguiente, se requiere el reclamo y el reconocimiento de la autodeterminación, el 
autogobierno y el desarrollo económico por parte del gobierno de ambos países y del mismo grupo étnico. Adicionalmente, se precisa incluir la consulta indígena, la migración trasnacional, las redes trasnacionales, además de optar por la revitalización de la cultura y la libertad de religión tal como este grupo lo considere relevante para sus integrantes.

\section{Yaquis en territorio yaqui, México y Estados Unidos: migración y redes trasnacionales}

La población yaqui se autodenomina yoeme, aunque es también conocida como yaqui, término que fue acuñado por los españoles. El grupo étnico es originario del río Yaqui, territorio aledaño al sur de Sonora, México. Su territorio se divide en ocho pueblos distribuidos a lo largo del río que lleva su nombre y mide aproximadamente medio millón de hectáreas. No obstante, también existe población yaqui en otros lugares de Sonora.

Respecto al contenido etnolingüístico, las y los yaquis tienen su propia lengua: jiak noki (Buitimea, Estrada, Grageda y Silva, 2016). Además, quienes viven en la república mexicana o territorio indígena hablan español; quienes viven en el medio angloparlante dominan el idioma inglés y/o español y, en ocasiones, también se presentan hablantes de la lengua jiak noki.

En los Estados Unidos, el grupo indígena se ubica principalmente en reservaciones de Arizona, así como en diferentes ciudades en California, Texas y Nuevo México. Desde finales de 1800 hasta mediados de 1900 se dieron grandes flujos migratorios de yaquis hacia Arizona, Texas, Nuevo México, California, Utah, Oregon y Nevada (Spicer, 1940a). La primera diáspora que llegó a EUA se dio durante la década de 1880, cuando el gobierno de Porfirio Díaz les declaró la guerra y emprendió una campaña en su contra; por tal motivo, la población yaqui se vio forzada a migrar a territorios menos amenazantes. Antes de ese periodo, las y los yaquis transitaban entre su territorio y el invadido por españoles desde Sonora-Sinaloa hasta California (Figueroa, 1985). Es importante señalar que es escasa la información sobre yaquis en lugares que no son el territorio yaqui: Yucatán, Sonora o Arizona.

En la actualidad la Tribu Pascua Yaqui (Pascua Yaqui Tribe, PYT) en Arizona cuenta con territorio propio y con el reconocimiento del gobierno federal como un pueblo indígena americano desde 1979. La población yaqui del sur de California 
fue registrada oficialmente en Riverside, California, en 2015 y conformada de manera informal desde 2009 (Rivera, 2020).

Christina Leza $(2015 ; 2018)$ argumenta que la comunidad yaqui ha sido dividida por políticas fronterizas estadounidenses y sus mecanismos coloniales; la separación geográfica e ideológica está amenazando a la población yoeme a pesar de que comparten lengua, historia, ceremonias y redes de apoyo transfronterizo (Leza, 2015). Sin embargo, cabe destacar que no solo han sido factores externos los que han dividido a la comunidad yaqui; también existen divisiones al interior del grupo étnico (Lerma, 2015; Vega, 2018). Por ejemplo, al ser una población indígena con ciudadanía estadounidense y raíces mexicanas enfrenta complejos procesos de construcción de la identidad; estos procesos pueden incluir una percepción cambiante con respecto a su nacionalidad, etnicidad y políticas. Concretamente, se pueden identificar como yaquis, mexicanos/as, estadounidenses o indígenas dependiendo del contexto (Leza, 2018). En este sentido, lo importante es recalcar que buscan mantener los lazos con las comunidades de origen, aunque enfrenten desafíos culturales.

Por otro lado, Héctor Vega (2018) destaca que el conflicto yoeme está conformado por una lógica de cooperación étnica trasnacional con ayuda de la PYT. El reconocimiento de la PYT como nación indígena es un dato sumamente importante para la historia de este grupo debido a que cambió completamente su situación económica y su relación de poder con el gobierno estadounidense y con el mexicano. Adicionalmente, activó —o reforzó- una identidad étnica trasnacional y se lograron afianzar lazos de solidaridad entre las dos naciones. Aparte, articuló la lucha jurídica en tribunales internacionales de la Organización de los Estados Americanos (OEA). Este caso de lucha indígena ejemplifica críticamente la existencia de procesos trasnacionales y dos dimensiones diferentes de acción de estas dinámicas: en primer lugar, la supraeconómica global, que es una dinámica en la esfera del capital financiero y de las megaempresas diseñadas de arriba abajo; en segundo lugar, el frente social de los pueblos indígenas (Vega, 2018: 125). En su análisis, Vega presenta a la población yoeme como un grupo trasnacional perteneciente a ambos lados de la frontera México-EUA e interesado en el reclamo de su derecho a la autodeterminación y al respeto de sus formas de gobierno, identidad y cultura (Vega, 2018: 127).

Durante los siglos XX y XXI, los yaquis han establecido redes trasnacionales, se han coordinado con los gobiernos de México y EUA y han reclamado y ganado reconocimiento federal de ambos Estados nacionales en diferentes momentos 
históricos (Schulze, 2018). Estas redes son parte de un campo social trasnacional establecido entre la comunidad indígena del río Yaqui, de la Tribu Pascua Yaqui, los yaquis de Texas y los yaquis de California. Conjuntamente, las redes incluyen otros grupos étnicos como navajos, tohono o'odham, apaches, gila river community, chumas, entre otros. De igual manera, se incluyen grupos no indígenas como comunidades mexicanas, mexicoamericanas y angloamericanas. Este vínculo trasnacional ha permitido, hasta nuestros días, el acceso formal y material a la justicia restaurativa para los yoemes. Las redes trasnacionales las mantienen unidas y unidos en su tierra y en tierras lejanas a través de lazos culturales y políticos. El grupo par del sur de California forma parte de estas redes trasnacionales por medio de sus prácticas ceremoniales, políticas y migratorias.

\section{Justicia para ambas comunidades yaquis: del río y del sur de California}

Resulta necesario mencionar que esta población étnica ha adoptado diferentes estrategias de supervivencia y de resistencia ante las oleadas de violaciones a sus derechos humanos y colectivos manifestadas en forma de exterminio, deportaciones masivas, falta de consulta indígena, despojo de tierras, entre otras. Como parte del reclamo de justicia restaurativa destaca la defensa de sus recursos sagrados; históricamente, la lucha yaqui ha sido por la tierra, el territorio, la cultura y demás recursos sagrados. Se han aventurado a negociar y colaborar con gobiernos nacionales, tribales y agencias internacionales por medio de mecanismos de participación local, nacional y trasnacional.

Las reivindicaciones por la justicia para el pueblo yoeme tienen respaldo en los instrumentos internacionales, domésticos y locales que se revisan a lo largo de este apartado. Van Ness (1996) sugiere que los tratados internacionales sobre derechos humanos ofrecen una forma de justicia restaurativa. Por lo menos, la teoría sobre justicia restaurativa puede proporcionar los medios conceptuales de normas y estándares internacionales para conciliar las aparentes incoherencias. Dicho autor analizó la Declaración Universal de los Derechos Humanos, el Convenio Internacional de los Derechos Económicos, Sociales y Culturales, el Pacto Internacional de los Derechos Civiles y Políticos, entre otros documentos del Compendio de Reglas y Normas de las Naciones Unidas en materia de prevención del delito y justicia penal; dentro de este examen se destaca el apoyo significativo a la teoría de la justicia restaurativa en los tratados internacionales de derechos humanos. 
A su vez, si trasladamos el estudio de los recursos internacionales de derechos humanos y la justicia restaurativa a los instrumentos en materia indígena tendríamos que incluir forzosamente la Declaración de la ONU sobre los derechos de los pueblos nativos y el Convenio núm. 169 de la OIT sobre pueblos indígenas y tribales en países independientes. Robert Williams (2005) hace énfasis en la importancia del derecho internacional sobre estos dos instrumentos, los cuales considera motores dentro de la reivindicación por la justicia étnica además de la defensa del territorio, la autodeterminación, la cultura y otros recursos. James Anaya (2009) menciona que la Declaración fue creada de acuerdo con las aspiraciones indígenas y los países han aceptado en parte seguir su dirección, aunque no impone obligaciones formales. Conjuntamente, otros instrumentos de derechos humanos internacionales que son vinculantes han reafirmado e incorporado los principios de la Declaración, tales como el Convenio núm. 169 de la OIT, el Comité para la Eliminación de la Discriminación Racial (CERD), la Convención sobre la eliminación de todas las formas de discriminación contra la mujer (CEDAW), entre otros (Anaya, 2009: 154).

En este sentido, vale la pena acentuar el valor del marco de los derechos humanos internacionales reflejado en la Declaración de las Naciones Unidas sobre los derechos de los pueblos indígenas (la Declaración) y en el Convenio núm. 169 de la OIT. En el contexto de los derechos humanos internacionales se subrayan las reivindicaciones por la justicia indígena, sobre todo en torno a la defensa del territorio, la autodeterminación, la cultura y otros recursos. Principalmente, los instrumentos internacionales de derechos humanos consideran que la cultura indígena (que incluye la autodeterminación, la defensa del territorio, entre otros) es un elemento inseparable de los derechos de los pueblos indígenas. Por ello, es preciso considerar la cultura en el marco de la justicia.

De una forma revolucionaria, la Corte Interamericana ha asociado los derechos de las poblaciones indígenas con el uso y gozo de la propiedad de la tierra y otros recursos considerando sus formas culturales dentro del artículo 21 de la Convención Americana de Derechos Humanos (CIDH, 1969). Por ejemplo, en los casos Awas Tingni versus Nicaragua $(\mathrm{CIDH}, 2001)$ y Saramaka versus Suriname, la Corte Interamericana determinó que los derechos de propiedad de las comunidades indígenas no son solo cuestión de posesión, sino que representan aspectos culturales y espirituales para las comunidades indígenas ( $\mathrm{CIDH}, 2007)$. En este contexto, la expansión de la Corte Interamericana sobre los derechos de propiedad de los pueblos indígenas y su cultura ha sido indispensable para 
concederles justicia y fortalecer sus lazos étnicos transnacionales (Williams, 2005). Asimismo, la ONU se ha pronunciado a favor de la protección de los derechos indígenas, enfatizando sus derechos culturales y formas colectivas de vida como aspectos vitales de su supervivencia (Cunningham, 2012).

A continuación se expone el modelo legal internacional que emana de la Declaración y del Convenio núm. 169 sobre el derecho a la autodeterminación, la autonomía, el autogobierno, la cultura, el territorio y otros recursos sagrados, así como sobre los derechos laborales, económicos, sociales y culturales. Dentro del modelo se resalta el derecho a una justicia restaurativa. Posteriormente, se presentan los recursos domésticos y tradicionales que abonan a este tipo de justicia para el caso yaqui.

\section{Declaración de las Naciones Unidas sobre los derechos de los pueblos indígenas}

La Declaración, aprobada en el 2007 por la Asamblea General de la ONU en Nueva York, EUA (ONU, 2008), es el más reciente y comprensible comunicado sobre los derechos de los pueblos indígenas (Tsosie, 2010). En general, promueve una ética de igualdad y afirma la igualdad de derechos, como individuos y como colectivos, además de disfrutar de los derechos humanos básicos prescritos en otros instrumentos de derechos humanos. Adicionalmente, la advierte que las y los indígenas deben estar libres de discriminación en el ejercicio de sus derechos (Tsosie, 2010: 216-218).

La Declaración (ONU, 2008) garantiza a los pueblos indígenas: el derecho a la autodeterminación, la autonomía, el autogobierno y la consulta (artículos 3, 4, 5, 13 y 19); los derechos culturales sobre identidad, espiritualidad, religión, educación, idioma, conocimiento ancestral, historia y transmisión a las futuras generaciones (artículos 11, 12, 13, 14, 16 y 31); los derechos sobre tierras, territorios y recursos naturales (artículos 10, 25, 26 y 32); los derechos laborales, económicos y sociales sobre salario, capacitación, desarrollo, salud, saneamiento, seguridad social, vivienda y medicina tradicional (artículos 17, 21, 22, 23 y 24); la igualdad de derechos entre hombres y mujeres (artículos 22 y 44); el derecho a mantener lazos institucionales, espirituales, políticos, sociales y transfronterizos (artículos 34 y 36) y el derecho a la justicia restaurativa (artículos 11, 13, 15, 21, 24, 26, 28, $29,31$ y 32$)$. 
Por lo tanto, la Declaración representa un instrumento internacional de derechos humanos crucial para los y las yaquis debido a que sus derechos colectivos, de autonomía y autodeterminación son plenamente reconocidos. Dichos derechos de autonomía y libre determinación, así como de autogobierno y consulta, brindan la posibilidad de remediar y resarcir los daños en torno a sus formas de gobierno y desarrollo. Igualmente, se permite utilizar un punto de vista indígena dentro de la justicia y la restauración. Los pasos anteriores son fundamentales dentro de la justicia restaurativa; asimismo los grupos de derechos mostrados permiten identificar colectivamente las violaciones de derechos sufridas históricamente, las necesidades a subsanar y las obligaciones de los Estados en el proceso de remediación de violaciones a los derechos humanos y colectivos de los pueblos nativos. En general, el último grupo de derechos enlistado aborda lo referente al derecho a la justicia restaurativa, aunque no necesariamente se incluye este término discursivo.

Los tratados internacionales sobre derechos humanos se pueden ver beneficiados con los lentes de la justicia restaurativa, por lo menos teóricamente, tal como argumenta Van Ness (1996). Dentro de la Declaración, específicamente, se pone énfasis en la participación de los Estados y de los pueblos indígenas como un paso primordial a la hora de procurar la restauración, restitución o, en la medida de lo posible, la compensación equitativa de los recursos comprometidos por el mismo Estado o por particulares. En el artículo 28 se destaca que las poblaciones nativas tienen ese derecho a la restauración, restitución o, en la medida de lo posible, a la compensación equitativa de sus tierras, territorios y recursos sagrados. En materia de restauración, los Estados tienen la responsabilidad de adoptar medidas eficaces para facilitar el ejercicio y asegurar la aplicación de los derechos establecidos bajo la Declaración. En este sentido, en 2008 se registró un caso exitoso en el que el gobierno de Canadá reconoció los derechos de los pueblos indígenas; había que sanar traumas infligidos y les ofreció un programa de reconciliación. Uno de los aspectos notables en la reposición fue el destacar a la cultura como tratamiento en la reconstrucción de lo sociocultural y el fortalecimiento de lo espiritual. Este enfoque considera los derechos humanos desde la perspectiva de las naciones indígenas como una forma de rehabilitación y justicia (Million, 2013: 117)D., \& ProQuest. (2013. 


\section{Convenio 169 de la OIT}

El Convenio núm. 169 de la OIT sobre pueblos indígenas y tribales en países independientes se adoptó en Ginebra, Suiza, en junio de 1989. Incluye la participación tripartita entre los gobiernos y las organizaciones de empleadores y de trabajadores (OIT, 2014: 6). Tiene dos postulados básicos: el derecho de los pueblos indígenas a mantener y fortalecer sus culturas, formas de vida e instituciones propias y el derecho a participar de manera efectiva en las decisiones que les afectan; asimismo, garantiza el derecho de los pueblos tribales a decidir sus prioridades en torno a sus procesos de desarrollo, así como el control, en la medida de lo posible, de su propio desarrollo económico, social y cultural (OIT, 2014: 8-9). La política general sobre la aplicación del Convenio se establece dentro del artículo 1, en el que se delimita quiénes son los pueblos tribales. Al respecto, cabe mencionar que la población yaqui cumple con esos requisitos.

Dentro del Convenio, los derechos que ilustran los artículos relacionados con la justicia que restaure las violaciones de derechos humanos que ha enfrentado este grupo étnico tienen que ver con el derecho a la acción coordinada entre gobiernos y pueblos (artículo 2); el derecho a la consulta indígena de buena fe y apropiadamente (artículo 6); el derecho a decidir sobre su propio desarrollo económico, social y cultural (artículo 7); el derecho a sus recursos naturales (artículo 15) y el derecho a la formación profesional, la artesanía e industrias rurales (artículo 21). Los artículos mencionados anteriormente representan los derechos más sobresalientes en la petición elaborada por los yaquis en México ante la CIDH y están relacionados con la justicia que restaure las violaciones de derechos humanos que ha enfrentado este grupo étnico. El Convenio aborda las demandas actuales e históricas yoeme; sobre todo, sintetiza las violaciones a derechos humanos que las y los yaquis han sufrido, tales como la falta de coordinación del gobierno con la población yaqui, la falta de consulta indígena, entre otros. Particularmente, el artículo 6 apunta a una justicia restaurativa con respecto a la participación coordinada entre los gobiernos y los pueblos indígenas por medio de la consulta previa, libre e informada. Determina que los gobiernos no deberán solo consultar a los grupos interesados, sino establecer los medios para el pleno desarrollo de las instituciones e iniciativas de esos pueblos y proporcionar los recursos para este fin. Sin duda alguna, la coordinación entre gobiernos y grupos étnicos es un elemento importante dentro de la justicia restaurativa al involucrar a las partes que han intervenido en una ofensa (violaciones de derechos humanos) en términos de ofensor, ofendido y comunidad; con ello se asegura una perspectiva étnica, 
coordinada, participativa y colectiva en la resolución de problemas históricos y actuales. No obstante, es preciso señalar que existe un desfase entre el marco jurídico internacional y la realidad que enfrentan las comunidades yaquis, sobre todo en el territorio yaqui en México.

\section{Constitución Política de México y de los Estados Unidos de América}

Acorde con la Constitución Política de los Estados Unidos Mexicanos, ${ }^{2}$ los pueblos indígenas son parte de la Nación independientemente de su adscripción étnica. A nivel constitucional, se garantiza que los pueblos indígenas tengan el reconocimiento del Estado mexicano por medio de los artículos 1, 2, 4 y 27. El artículo 1 (reformado en 2011) de la Constitución incluye los tratados de derechos humanos firmados por México en una sola plataforma de derechos. En este marco, México tiene obligaciones formales de respetar esos tratados como parte de la Constitución. Este mismo artículo instituye que los pueblos tribales no serán discriminados por motivos de origen étnico, nacionalidad, género, edad, condición social, religión o cualquier otra razón que constituya una ofensa a la dignidad humana y cuyo objetivo sea anular o socavar los derechos y libertades individuales.

Pese a que el marco constitucional mexicano es muy claro sobre las garantías indígenas, existe discordancia con la realidad que enfrentan los yaquis del río. El día a día en los pueblos yaquis es adverso, sin seguridad alimentaria e hídrica; además, está presente el despojo de tierras, el «rentismo», la violencia, el racismo, la falta de consulta indígena sobre proyectos de desarrollo, entre otros problemas.

Concretamente, el artículo 2 de la Constitución mexicana garantiza el derecho de los pueblos indígenas a la autodeterminación, el autogobierno y la autonomía de sus valores culturales, políticos, sociales y económicos. Desde su reforma en 2001, este artículo establece que México es un país multicultural basado en su población indígena. Es importante señalar que el artículo 4 también se reformó en 2001 y que se incorporaron los derechos culturales, derechos de libre determinación y la autonomía de los pueblos indígenas al artículo 2 (Herrera, 2015; IWGIA, 2018). Sin embargo, en el actual artículo 4 constitucional aún destaca el derecho a la cultura y al ejercicio de los derechos culturales en general. En par-

\footnotetext{
${ }^{2}$ Constitución Política de los Estados Unidos Mexicanos. Texto vigente. Última reforma publicada en el Diario Oficial de la Federación, 08-05-2020, disponible en <http://www.diputados.gob.mx/ LeyesBiblio/pdf/1_080520.pdf> (consulta 11/06/2020).
} 
ticular el artículo 2 brinda derechos pluriculturales a los pueblos indígenas en el marco del derecho a la libre determinación y autonomía en un país multiétnico, aunque asegurando la unidad nacional. ${ }^{3}$

Por su parte, el artículo 27 constitucional, fracción VII, protege la integridad de los grupos indígenas. Si bien es cierto que la Constitución estipula eso, la reforma de este artículo en 1992 transformó el título colectivo indígena en ejidal. Aunque a nivel simbólico los yaquis siguieron teniendo éxito en la propiedad colectiva de la tierra, después de la reforma agraria capitalista de 1992 la economía local del pueblo yoeme, que dependía de la agricultura, experimentó un fracaso a nivel material (Molina, 2013). Esta reforma exigía un título de propiedad para otorgar préstamos y créditos, lo que colocó al pueblo indígena y a su propiedad colectiva de la tierra en una situación de desventaja en comparación con los inversionistas ricos (no indígenas), quienes sí poseían dichos títulos. Después de esta reforma, solo 17.8 \% de los yaquis continuó trabajando en actividades agrícolas porque pudieron demostrar la documentación requerida, el resto subsistía del comercio informal, de las actividades ganaderas y de actividades económicas nacionales. Como resultado, el pueblo indígena tuvo que alquilar más de $90 \%$ del territorio yaqui a inversionistas extranjeros (Zárate, 2016). La reforma del 27 constitucional detonó exclusión y discriminación en comparación con quienes podían verificar tenencia de la tierra para solicitar recursos económicos. Por otro lado, el gobierno mexicano adquirió derechos para otorgar concesiones sobre tierras y territorios a particulares y empresas trasnacionales, legitimando así el despojo del territorio indígena.

Desafortunadamente, la Constitución de EUA no cuenta con los mismos equivalentes. Por un lado, porque posee un sistema jurídico diferente; por otro, debido al racismo sistémico y fundacional al cual alude Feagin (2006). La Constitución menciona a los pueblos indígenas dentro del artículo 1, sección 8 y la enmienda 14; el primer artículo establece que el Congreso tiene el poder de regular las relaciones comerciales con tribus indígenas, entre otras entidades (US National Archives, s/f) y la enmienda 14 aborda lo relativo al derecho a la ciudadanía, en la que se excluye a indígenas libres de impuestos. Lo anterior significa que no

\footnotetext{
${ }^{3}$ Véase «Decreto por el que se reforma la fracción III, del Apartado A, del artículo 2 de la Constitución Política de los Estados Unidos Mexicanos», Diario Oficial de la Federación (Primera Sección), 22 de mayo de 2015, disponible en <http://www.ordenjuridico.gob.mx/Documentos/ Federal/wo103033.doc> (consulta 01/01/2019). Y «Decreto por el que se adiciona el artículo 4 de la Constitución Política de los Estados Unidos Mexicanos», Diario Oficial de la Federación (Primera Sección), 17 de junio de 2014, México, disponible en: <http://www.ordenjuridico.gob.mx/ Constitucion/reformas/DEC18062014.doc> (consulta 01/01/2019).
} 
contempla en su totalidad a las poblaciones indígenas como candidatas al derecho de ciudadanía (Beck, 2004). Algunos académicos especializados en jurisprudencia indígena argumentan que debido a la falta de normativa indígena en EUA, es necesario recurrir al derecho internacional por medio de los instrumentos internacionales de derechos humanos sobre pueblos indígenas (Anaya, 2009; Williams, 2005). Para el caso mexicano, así lo fue antes de que en la Constitución mexicana se reconocieran los pactos e instrumentos internacionales en derechos humanos como parte de su normatividad dentro del artículo 4 constitucional.

\section{Decreto de Cárdenas}

En 1940, el entonces presidente de México, Lázaro Cárdenas, reconoció los derechos autónomos y de territorio de la población yaqui mediante el decreto presidencial conocido como Decreto de Cárdenas. Este documento representa un primer intento de justicia restaurativa para las y los yoemes. En 1937, el acuerdo estaba enfocado en resolver el problema agrario del Valle del Yaqui, así como la ubicación de los terrenos restituidos a la sociedad yaqui. Por este medio, el gobierno de México decretó la restitución de tierras de riego, pastos, montes y cerriles para la tribu yaqui del estado de Sonora como un mecanismo de remediación de daños perpetuados por el gobierno mexicano hacia el pueblo yaqui (Figueroa, 1985: 113-114). Dicho acuerdo generó dos disyuntivas: por un lado, involucró la restauración de las tierras y la autonomía política; por otro, envolvió un nuevo sistema de opresión y explotación que generó, a su vez, la pérdida del control sobre los procesos de desarrollo y propiedad territorial indígena (Figueroa, 1985: 121). En este sentido, es notorio que las autoridades tradicionales aún utilizan este recurso doméstico para dar soporte jurídico a su lucha por la defensa de la tierra y demás recursos sagrados; sin embargo, en términos materiales, no ha tenido el impacto deseado sobre la recuperación de tierras y otros recursos. Desafortunadamente, las violaciones de derechos humanos continúan hasta nuestros días.

\section{Demanda ante la Comisión Interamericana de Derechos Humanos (CIDH)}

La demanda 79-06 ante la CIDH contra el Estado mexicano es una apuesta por la justicia que restaure la situación del pueblo del río Yaqui ante el despojo sistemático de territorio y otros recursos sagrados. Castro (2020) menciona que en 2011 
las autoridades tradicionales del río presentaron una petición y posteriormente una solicitud de medidas cautelares. La demanda fue interpuesta por la población yoeme ante el organismo internacional con ayuda de sus pares de Arizona y un grupo de trabajo trasnacional. Esta solicitud se asoció con las observaciones finales del Comité para la Eliminación de la Discriminación Racial (CERD) que tratan la situación del caso yaqui del río. Dentro de esta demanda se afirmó que las y los yaquis tienen derecho a consultar inmediatamente al gobierno de México sobre el problema de la crisis de salud y mortalidad infantil a causa de la contaminación y el despojo del agua del río Yaqui. De manera adicional, la petición incluye dentro de sus demandas la corrupción relacionada con la consulta indígena sobre el gasoducto de Aguaprieta, el acueducto Independencia y las repercusiones de estos proyectos desarrollistas (hundimientos, salinización, sequía y otras condiciones desfavorables de la tierra), así como la falta de determinación con respecto a la situación precaria de los profesores indígenas.

Además, por medio de la demanda se solicitó a la CIDH que el Estado mexicano subsane diferentes derechos — violados- contenidos en la Convención y en la Declaración Americana (Foro Regional Indígena, 2016). En particular, México, como Estado parte de la OEA, ha reconocido ambos instrumentos y ha aceptado la intervención de la Corte Interamericana de Derechos Humanos.

En el marco de la Convención Americana de Derechos Humanos, la mencionada demanda yaqui solicitó a la $\mathrm{CIDH}$ que el Estado mexicano restaure el derecho a no ser discriminado (artículo 1), el derecho a efectos legales internos (artículo 2), el derecho a la vida (artículo 4), el derecho al trato humano (artículo 5), el derecho a un juicio justo (artículo 8), los derechos de la niñez (artículo 19), el derecho a la propiedad (artículo 21), el derecho a participar en el gobierno (artículo 23), el derecho a la igualdad (artículo 24), el derecho a la protección judicial (artículo 25) y el derecho al desarrollo (artículo 26). Los apartados reclamados dentro de este instrumento están relacionados con la justicia restaurativa. Legítimamente, las y los yoemes declaran que estos derechos han sido violados por el Estado mexicano. En particular, todos los artículos incumplidos anteriormente denotan las injusticias que la población necesita reivindicar e identifican las obligaciones a cumplir por parte del gobierno. Por otro lado, pese a que no se utiliza el discurso de la justicia restaurativa dentro de estos artículos, sí se aborda y se establece de manera específica el derecho a la justicia y la protección judicial dentro de los artículos 8 y 25, respectivamente. Además, se fija el derecho a la compensación justa, que se encuentra citado dentro del artículo 10. En la medida que es- 
tos derechos se acaten por los Estados parte, las poblaciones indígenas tendrán posibilidades de sanar y remediar las violaciones a sus derechos individuales y colectivos. Obviamente, se requiere la participación tanto del pueblo indígena como de todos los niveles de gobierno e incluso la intervención de la comunidad en general. Esta estrategia forma parte fundamental de la justicia restaurativa.

Asimismo, utilizando la Declaración Americana de los Derechos y Deberes del Hombre (CIDH, 1948), la población yaqui reclama ante la $\mathrm{CIDH}$ el derecho a la vida, a la libertad, a la seguridad e integridad de la persona (artículo I), derecho de igualdad ante la ley (artículo II), derecho de protección a la maternidad y a la infancia (artículo VII), derecho a la preservación de la salud y al bienestar (artículo $\mathrm{XI}$ ), derecho de justicia (artículo XVIII), derecho de sufragio y de participación en el gobierno (artículo XX) y derecho a la propiedad (artículo XXIII). Los artículos reclamados están estrechamente vinculados a la justicia restaurativa; sin embargo, el artículo XVIII establece directamente el derecho de justicia, estipulando que toda persona puede acudir a los tribunales para hacer valer sus derechos mediante procedimientos sencillos y breves, y la justicia puede amparar contra actos de la autoridad que violen derechos fundamentales. En el contexto de la justicia restaurativa es indispensable contar con procesos jurídicos accesibles a todas las personas que así lo requieran. Finalmente, en 2015 la CIDH consideró que la petición 79-06 tiene fundamento, de conformidad con los artículos 1, 2 y 21 de la Convención Americana, así como con el artículo XXIII (sobre el derecho a la propiedad) de la Declaración Americana (Castro, 2020: 65). Los artículos 1 y 2 de la Convención Americana tienen que ver con el derecho a no ser discriminado y el derecho a efectos legales internos, respectivamente. El artículo 21 de la Convención Americana aborda los derechos de propiedad y se asocia con los derechos culturales indígenas por parte de la Corte Interamericana. La consideración de la $\mathrm{CIDH}$ es un paso revolucionario, pues contempla la unión del artículo 21 con otros derechos internacionales tales como el derecho a la consulta indígena, a la libre determinación, a un juicio justo, entre otros. Los casos que han utilizado esta estrategia exitosamente son Saramaka versus Surinam (2007), Awas Tingni versus Nicaragua (2001) y Sarayaku versus Ecuador (2012). Estos casos han sido fundamentales en la progresión de la jurisprudencia internacional de los pueblos indígenas, debido a que reafirman los derechos a controlar sus tierras, territorio y recursos naturales, estableciendo una asociación especial con los derechos culturales y de consulta (Cunningham, 2012; Williams, 2005). Estos casos también ofrecen una opción legal para la población yoeme. 
De acuerdo con Héctor Vega, la demanda ante la CIDH consolida una estrategia de lucha transnacional para la integridad del territorio indígena que materializa y simboliza el problema de proyectos extractivistas que usufructúan el territorio y demás recursos indígenas en el nombre del capital trasnacional (Vega, 2018:131-132).

\section{Acciones legales y sociales con injerencia internacional}

En México, la población yoeme interpuso amparos en contra la construcción de dos proyectos desarrollistas: el acueducto Independencia y el gasoducto de Aguaprieta. Estos recursos jurídicos demandan que el Estado mexicano, en contubernio con compañías trasnacionales, primero viola el derecho a la libre determinación y a una consulta indígena apropiada para el pueblo yaqui; posteriormente viola la Ley de amparo de México (CEMDA, 2012). Aunado a estos litigios domésticos, se realizaron marchas, plantones y otras protestas sociales no solo en territorio étnico, sino a nivel nacional e internacional. Por otro lado, la migración trasnacional ha sido otro recurso empleado históricamente para desestabilizar al Estado mexicano, sobrevivir y resistir (Hu-DeHart, 1984; 1995; Schulze, 2018). Para el caso de yaquis en California, la migración les ha dado la posibilidad de tener acceso a recursos laborales, económicos y sociales para poder subsistir y seguir ayudando a su gente de los pueblos del río Yaqui. Asimismo, los lazos étnicos trasnacionales posibilitan la continuidad de las prácticas culturales indígenas incluso en los Estados Unidos.

\section{Propuesta de iniciativa de ley Indígena}

En 2016, las autoridades tradicionales indígenas de la comunidad yaqui presentaron la «Propuesta de iniciativa de Ley Indígena para el Estado Libre y Soberano de Sonora, que presenta la tribu yaqui a la 61 Legislatura del H. Congreso del Estado de Sonora» dentro del Foro Regional Indígena (2016), ${ }^{4}$ organizado por la Comisión de Asuntos Indígenas del H. Congreso del Estado de SonoraLegislatura 2015-2018, la Comisión Nacional para el Desarrollo de los Pueblos Indígenas y la Comisión Estatal para el Desarrollo de los Pueblos y Comunidades Indígenas (CEDIS). Los temas centrales abordados dentro del foro y de la propues-

\footnotetext{
${ }^{4}$ Foro Regional Indígena, Comisión de Asuntos Indígenas del H. Congreso del estado de Sonora, Legislatura 2015-2018, CNDPI y CEDIS, Pótam, Sonora, México, 29 de abril de 2016.
} 
ta de ley indígena fueron el derecho al reconocimiento como población indígena, la autonomía, el territorio indígena, el reconocimiento de los sistemas jurídicos tradicionales, el desarrollo desde el punto de vista propio y la consulta indígena. En la propuesta de ley indígena se plantea la armonización de los derechos individuales con los derechos colectivos de manera interdependiente. Asimismo, se tomó como base la demanda 79-06 ante la CIDH, por ende, también se consideró la Convención y la Declaración y el tratado de Cárdenas, así como la Constitución mexicana y el protocolo yoeme. El trasfondo de la propuesta de ley indígena es restaurar las violaciones históricas de derechos humanos perpetuadas por el gobierno mexicano y compañías extractivas, además de avanzar en materia de derecho consuetudinario.

En el 2019, las autoridades tradicionales desarrollaron el «Plan de Justicia Yaqui: territorio, agua y desarrollo. Acuerdo presidencial/INPI y Autoridades Tradicionales de la Tribu Yaqui» a partir de la visita a Pótam del actual presidente de México, Andrés Manuel López Obrador. El Plan de Justicia contempla tres ejes de análisis: territorio, agua y desarrollo; impulsa la transversalidad consuetudinaria al conciliar y mediar el protocolo y la ley interna indígena con el derecho constitucional mexicano e internacional de los derechos indígenas.

Los instrumentos emitidos por las autoridades tradicionales tienen una base de justicia restaurativa incluso sin el uso de su terminología. Adicionalmente, demuestran que aún se mantiene viva la exigencia histórica de ser reconocidos como grupo indígena con plena capacidad para ejercer su derecho a la libre determinación y autonomía, a establecer su propio gobierno, elegir su propio desarrollo y a ser consultados ante proyectos que les afecten. Este reconocimiento se identifica colectivamente como una necesidad y, a su vez, se plantea como una solución a las violaciones de derechos humanos que han sufrido. Asimismo, demuestran un esfuerzo por trabajar en coordinación con el gobierno mexicano en la restauración de los derechos que se han visto despojados. También se destacan los esfuerzos por coordinar leyes consuetudinarias, domésticas e internacionales. Sin duda alguna, se busca utilizar una perspectiva indígena dentro del panorama de la restauración de daños, sin buscar culpables, sino soluciones a problemas históricos y estructurales. Todos estos puntos son los pilares de la justicia restaurativa. 


\section{Procedimientos especiales de la Organización de las Naciones Unidas (ONU)}

Las acciones interpuestas ante el Sistema Internacional de Derechos Humanos, mediante la oficina de procedimientos especiales de la ONU sobre asuntos indígenas, han dado un especial giro a la lucha por la justicia yoeme (CEMDA, 2012: 4). La ONU ha seguido muy de cerca las violaciones sistémicas de derechos humanos que el Estado mexicano ha cometido respecto al caso yaqui del río, tanto por sí mismo como por compañías privadas. El organismo internacional ha emitido varios documentos sobre este caso, se ha reunido con integrantes indígenas y ha realizado múltiples visitas de campo para corroborar la situación del pueblo yaqui. En general, se establece que los reclamos yoeme giran principalmente en torno a la defensa de la tierra, otros recursos sagrados y la autodeterminación (Alto Comisionado de las Naciones Unidas, 2016; ONU-DH, 2018; Stavenhagen, 2003). A los conflictos indígenas se les adicionan otro tipo de problemas tales como la criminalización de las protestas y la disidencia social, la impunidad y la corrupción así como la discriminación racial hacia mujeres, niños, niñas y migrantes indígenas (Stavenhagen, 2003: 18).

En el 2016, la ONU se reunió con representantes de varios casos emblemáticos de Sonora, como la comunidad yaqui del río. Dentro de esta reunión se expusieron las violaciones de derechos humanos y colectivos que este grupo étnico ha sufrido por parte de compañías privadas con ayuda de las autoridades mexicanas, como el despojo de tierras y aguas, la falta de consulta indígena sobre proyectos de desarrollo trasnacional y la discriminación racial constituyen algunas de ellas. Los reclamos se relacionan con el derecho a la libre determinación, así como a la consulta indígena, el medio ambiente, la salud, la educación, entre otros derechos (Alto Comisionado de las Naciones Unidas, 2016).

En el 2017, representantes de la ONU asistieron al Foro Binacional sobre Derecho y Medio Ambiente en el río Yaqui. Tanto autoridades tradicionales como integrantes en general del grupo indígena (del río Yaqui y PYT) manifestaron la situación vulnerable que permea en su territorio, con un especial énfasis en la situación del río y la contaminación de sus aguas. Durante dicho evento también se reunieron académicos, investigadores y sociedad civil, además de integrantes de la ONU y autoridades yoemes, para debatir sobre el derecho y medio ambiente en el río Yaqui proclamando reconocimiento como pueblo indígena con derecho a la autodeterminación mediante la autonomía. 
Concretamente, la ONU ha tenido un papel transcendental al destacar internacionalmente e identificar de manera colectiva las injusticias sufridas por las y los yoemes. Estas necesidades a reparar y obligaciones por cumplir son un primer paso hacia la justicia restaurativa; así, se podrán subsanar las malas prácticas en las que el Estado ha incurrido por acción u omisión. Asimismo, es vital el vincular actores nacionales, internacionales e indígenas en el proceso de justicia. En especial es fundamental utilizar una óptica indígena dentro del paradigma de la restauración. Sin duda alguna, el papel protagónico lo ocupa la comunidad yoeme por haber emprendido una lucha histórica y organizada en torno a la defensa de sus recursos sagrados.

\section{Yaqui Nation of Southern California (YNSC)}

La Constitución política de la YNSC establece que es una población nativa americana soberana. El grupo se constituyó formalmente en el 2015 en el condado de Riverside, California, EUA. Está compuesto por aproximadamente 90 integrantes inscritos. Quienes integran el grupo grupo viven en domicilios particulares cerca de sus trabajos y centros ceremoniales, principalmente en el Valle de Coachella y Los Ángeles, California. También, hay quienes residen en Tucson, Arizona, cerca de la reservación indígena PYT. Cabe destacar que, más que una comunidad localizada en un punto geográfico determinado, la YNSC es una comunidad étnica con lazos trasnacionales entre diferentes grupos indígenas, grupos no indígenas, México y los Estados Unidos.

Es necesario subrayar que la YNSC tiene el reconocimiento cultural y político de sus pares del río Yaqui; además, se estipula el reconocimiento de la colaboración trasnacional, el reconocimiento de la ubicación, existencia y parentesco. ${ }^{5}$

Respecto al parentesco existen relaciones consanguíneas y de compadrazgo, y quienes integran la YNSC siempre reportan un «lado yaqui de la familia». La mayoría tiene lazos familiares en México, ya sea por su lugar de nacimiento o por parentesco directo; además, existen relaciones con otros grupos indígenas en México y EUA. Las relaciones con otros grupos yoemes se dan por la búsqueda constante de familiares en el río Yaqui, en México; también por los deseos de conocer o explorar sus relaciones con yaquis y por el establecimiento de contacto con sus pares indígenas en EUA y México. En particular, el artículo 36 de la

\footnotetext{
${ }^{5}$ Carta de agradecimiento y reconocimiento hacia la Yaqui Nation of Southern California de las autoridades tradicionales de Loma de Guamúchil, pueblo Yaqui, Sonora, México, 2016.
} 
Declaración cobra relevancia para las y los yaquis como un grupo transfronterizo donde se establece que «tienen derecho a mantener y desarrollar los contactos, las relaciones y la cooperación, [...] con sus propios miembros, así como con otros pueblos, a través de las fronteras» (ONU, 2008: 13). Este derecho ha sido violado de manera constante debido a la separación geográfica y política entre México y EUA; sin embargo, el grupo étnico se ha encargado de reivindicar este derecho históricamente.

Las estrategias que la YNSC desarrolla están encaminadas a la reproducción cultural y social del grupo étnico. Sus principales actividades son reivindicar el derecho al autogobierno y la autodeterminación mediante el establecimiento de la autoridad étnica y el consejo de mayores, enseñar a las nuevas generaciones sobre sus ceremonias e historia, precisar procedimientos para la adscripción étnica y organizarse como grupo en general. Otra de las actividades es la práctica de diversas ceremonias indígenas como la danza del venado, danza del coyote, Cuaresma Pascua, Semana Santa, danza del oso, danza del sol, ceremonia de la visión, el uso de medicinas tradicionales y del temazcal. Cabe destacar que las ceremonias de la visión y del temazcal, así como las danzas del oso y del sol, no son propias de los yaquis de los ocho pueblos yoemes, sino influencia de otros grupos nativos de EUA y Mesoamérica; por otro lado, las ceremonias de Cuaresma, Pascua y Semana Santa son ritos occidentales que la población yaqui adoptó sincréticamente como suyos (Erickson, 2008; Figueroa, 1985, 1993, 1994; Gouy-Gilbert, 2015; Lerma, 2015; Moctezuma, 2001; Olavarría, 2003; Padilla y Reyes, 2015; Padilla et al., 2012; Spicer, 1940b, 1958, 1980).

Adicionalmente, quienes integran la YNSC se dedican a apoyar a los pueblos del río Yaqui por medio de donaciones e intercambios materiales y culturales. Todas estas prácticas tienen sustento dentro del derecho internacional y son la base para la reparación de violaciones a sus derechos como grupo indígena.

Respecto a las visiones sobre justicia restaurativa que tienen los miembros de la YNSC, se destaca la responsabilidad del gobierno mexicano y estadounidense ante las violaciones de derechos humanos y colectivos hacia la población yaqui. La visión sobre su futuro se relaciona con el reconocimiento del grupo étnico, el sufrimiento de los antepasados yoemes, el territorio ancestral y la adquisición de un territorio étnico en California. La justicia para las comunidades yaquis del río y del sur de California tiene que ver con la consideración de esas visiones y la aplicación de las medidas propuestas local, estatal e internacionalmente, incluyendo la luturia. Hay que destacar que la luturia es parte fundamental para las y los ya- 
quis, además de ser el hilo conductor de las relaciones trasnacionales étnicas. La luturia se entiende como la «verdad suprema» de su conocimiento ancestral. Esta incluye comportamientos éticos, el cumplimiento de roles y responsabilidades, la devoción a Dios, el servicio comunitario, los valores de solidaridad, justicia, trabajo cooperativo, ceremonias, rituales, protección de los ancianos, mujeres y niños, así como la defensa del territorio yaqui y otros bienes naturales. Cabe mencionar que las normas yaquis existen para proteger a la luturia y viceversa (Lerma, 2015).

\section{Consideraciones finales}

La violación sistemática de derechos humanos y colectivos que ha enfrentado la población yoeme en torno a la tierra, el agua y otros recursos sagrados amerita justicia que restaure esas violaciones. A lo largo de este artículo se examinó el modelo de justicia restaurativa y su importancia respecto a las comunidades yaquis del río y del sur de California. Se destacan las opciones legales - a favor de la lucha yoeme- que proclaman la autodeterminación y autonomía tanto en los pueblos del río como en California, EUA. En concreto es posible decir que en el río Yaqui existe una disonancia entre el marco jurídico y la realidad yoeme. La población yaqui ha desarrollado una defensa histórica y organizada, pero aún existe un largo camino por recorrer.

Las y los yaquis proclaman una justicia que reivindique su derecho a la autodeterminación y soberanía de sus prácticas culturales, sociales y políticas, así como a proteger su religión, educación, alimentación, lengua, territorio, economía y gobierno. Dichos reclamos se llevan a cabo en forma de acciones directas y litigios domésticos e internacionales. Asimismo, la comunidad yaqui del sur de California proclama justicia a través de sus prácticas ceremoniales y de movilidad trasnacional para darle continuidad a su cultura. Dentro de un contexto fronterizo, la población yoeme hace uso del espacio étnico trasnacional, nacional, regional y global con el objetivo de difundir sus reclamos y demandas tanto en México como en EUA (Vega, 2018). A nivel político, social y cultural la población yaqui del río y del sur de California ha construido, con otras comunidades indígenas y no indígenas, una alianza integrada por una red étnica transnacional. El derecho consuetudinario y la luturia tienen un papel protagónico dentro de esta estrategia al legitimar el conocimiento ancestral indígena en coordinación con el derecho positivo nacional e internacional. Cabe destacar que las y los yoemes han ge- 
nerado espacios trasnacionales para llevar a cabo procesos de negociación con el gobierno e instituciones internacionales, se han organizado foros indígenas así como reuniones con congresos locales y nacionales, así como con la ONU y la $\mathrm{CIDH}$. Han establecido alianzas con otras poblaciones indígenas y no indígenas a escala global e incluso se han involucrado con movimientos locales, nacionales e internacionales al igual que con instituciones de gobierno, académicas y privadas para la producción de un conocimiento transfronterizo.

En general, los tratados internacionales sobre derechos humanos ofrecen, por lo menos teóricamente, una forma de justicia restaurativa (Van Ness, 1996: 31). En ellos se indica que los Estados deben equilibrar los intereses de las víctimas y los victimarios; que todas las partes involucradas deben tener acceso a mecanismos justos de solución y que se requiere una acción integral del gobierno y la comunidad (Van Ness, 1996: 17).

Pese a la abundante jurisprudencia y las propuestas en materia de justicia internacional, nacional y local para las poblaciones indígenas, es vital hacer énfasis en la constante violación de derechos humanos y colectivos a la que ha estado sujeta la población yoeme. Se requiere la reparación de los daños infligidos por el gobierno mexicano, norteamericano y compañías privadas trasnacionales hacia yaquis en ambos lados de la frontera de México y EUA. La defensa de la tierra, la cultura y demás recursos sagrados está amparada por el derecho internacional, constitucional y consuetudinario. La justicia restaurativa sirve como marco de referencia teórica para abordar las reparaciones necesarias e integrar las discrepancias jurídicas considerando el conocimiento tradicional yoeme, la luturia, las ceremonias, los lazos interétnicos y la migración trasnacional. Por un lado, dentro del marco de la justicia restaurativa se identifican colectivamente las necesidades que tienen como pueblo indígena debido a las violaciones de derechos humanos por parte de gobiernos pasados y presentes; por otro, como una medida de remediación se reivindican los derechos a la autodeterminación, el autogobierno, la autonomía y la elección de los procesos de desarrollo en sus propios términos. También se trata de involucrar al Estado mexicano y americano, así como a sus pares indígenas en Estados Unidos, como parte de la estrategia por la justicia restaurativa.

Las opciones de defensa legal para el pueblo yaqui en México y EUA requieren incluir el punto de vista holístico de la vida que la población yoeme posee, además de las reivindicaciones yaquis sobre la defensa de su cultura, territorio y otros recursos sagrados. Lo anterior tiene un fundamento claro y preciso dentro

\section{4}

Revista Pueblos y fronteras digital • volumen 16 • 2021, pp. 1-30 • ISSN 1870-4115 
de los instrumentos internacionales e indígenas, principalmente avalados por la Declaración de las Naciones Unidas sobre los derechos de los pueblos indígenas (ONU, 2008) y por el Convenio núm. 169 de la OIT (OIT, 2014). Dentro de la Declaración, el artículo 26 les otorga a las poblaciones indígenas el derecho a controlar sus tierras y sus recursos y este mismo derecho está ligado a la cultura y a la consulta indígena en otros instrumentos como el artículo 6 del Convenio núm. 169. El derecho a la autodeterminación, la autonomía, el autogobierno y la consulta indígena se formulan en los instrumentos de derechos humanos, especialmente en la Declaración dentro de los artículos 3, 4, 5, 13 y 19. Además, la Declaración establece el derecho a la justicia restaurativa en los artículos 11, 13, 15, 21, 24, 26, 28, 29, 31 y 32. Asimismo, el Convenio núm. 169 de cabida a la justicia restaurativa dentro del artículo 6 con el derecho a la participación coordinada entre los gobiernos y los grupos indígenas por medio de la consulta indígena y la cultura. Por otro lado, la Constitución mexicana da soporte a las poblaciones indígenas dentro del territorio de México en los artículos 1, 2, 4 y 27. Desafortunadamente, no se puede decir lo mismo de la Constitución de EUA. Por lo tanto, es importante la implementación de instrumentos internacionales de derechos humanos. En la actualidad los gobiernos indígenas están en condiciones de ejercer su soberanía cultural a fin de proteger los derechos humanos de sus integrantes en torno a la supervivencia cultural y la autodeterminación (Tsosie, 2010). En sí, la pregunta no es si las poblaciones indígenas tienen derecho a la soberanía, la autodeterminación, la autonomía o la cultura, sino cómo los Estados pueden respetar, procurar y restaurar esos derechos a nivel simbólico y material.

\section{Agradecimientos}

Especiales agradecimientos al pueblo yoeme por ser un ejemplo de persistencia y resistencia. Igualmente, agradecimientos al Consejo Nacional de Ciencia y Tecnología (Conacyt), particularmente por la beca posdoctoral dentro del marco de la convocatoria «Estancias Posdoctorales en el Extranjero, Vinculadas a la Consolidación de Grupos de Investigación y Fortalecimiento del Posgrado Nacional 2018-2020», al Instituto Binacional de Migraciones y al Programa de Pueblos Indígenas de la Universidad de Arizona, así como al Posgrado Interdisciplinario en Ciencias Sociales de la Universidad de Sonora. Este trabajo es producto de dicho programa posdoctoral y del grupo de investigación trasnacional. 


\section{Bibliografía citada}

Alto Comisionado de las Naciones Unidas. (2016). Declaración del Grupo de trabajo de Naciones Unidas sobre empresas y derechos humanos al final de su visita a México, disponible en: <https://www.ohchr.org/sp/NewsEvents/Pages/DisplayNews.aspx?NewsID=20466\&LangID=S> (consulta: 12/12/2016).

Anaya, James. (2009). International Human Rights and Indigenous Peoples. Austin, Texas: Wolters Kluwer Law \& Business.

Beck, George. (2004). The Fourteenth Amendment as Related to Tribal Indians: Section I, "Subject to the Jurisdiction Thereof" and Section II, "Excluding Indians Not Taxed", American Indian Culture and Research Journal, 28(4), pp. 37-68, doi: 10.17953/ aicr.28.4.m74ml521484qr2xj

Buitimea, Crecencio, Zarina Estrada, Aarón Grageda y Manuel Silva. (2016). Diccionario yaqui de bolsillo Jiak noki-español/español-jiak noki. Sonora, México: Universidad de Sonora.

Bustamante, Javiera y Alejandra Carreño. (2020). Reparación simbólica, trauma y victimización: la respuesta del Estado chileno a las violaciones de derechos humanos (1973-1990). Íconos - Revista de Ciencias Sociales, XXIV(67), pp. 39-59, doi: 10.17141/ iconos.67.2020.4231

Castro, Elia. (2020). Yaqui Women's Community Development the Rio Yaqui Pueblos: An Emerging Model for Indigenous Human Rights. Tesis de doctorado en ciencias jurídicas. Arizona: University of Arizona Law.

Centro Mexicano de Derecho Ambiental (CEMDA). (2012). Caso de la Tribu Yaqui y el Acueducto Independencia. Despojo de agua y del territorio tradicional, Informe. México, disponible en: <http://cendoc.docip.org/collect/cendocdo/index/assoc/ HASH611c/47452e36.dir/PF17Yaqui030ES.pdf> (consulta: 18/06/20).

Comisión Interamericana de Derechos Humanos (CIDH). (1948). Declaración Americana de los Derechos y Deberes del Hombre, 1948, Bogotá, Colombia, disponible en <http://www.ordenjuridico.gob.mx/TratInt/Derechos\%20Humanos/INST\%2004. pdf> (consulta 01/07/2020).

Comisión Interamericana de Derechos Humanos (CIDH). (1969). Convención Americana de Derechos Humanos, disponible en <https://www.oas.org/dil/esp/tratados_b32_ convencion_americana_sobre_derechos_humanos.htm> (consulta 01/07/2020).

Comisión Interamericana de Derechos Humanos (CIDH). (2001). Caso Awas Tingni v. Nicaragua, Judgment, series C, núm. 79, IACHR 9.

Comisión Interamericana de Derechos Humanos (CIDH). (2007). Caso Saramaka v. Suriname, Judgment, series C, núm. 172, IACHR 5.

Comisión Interamericana de Derechos Humanos (CIDH). (2012). Caso Pueblo Indígena Kichwa de Sarayaku vs. Ecuador, sentencia, 2012, disponible en: <https://corteidh. or.cr/docs/casos/articulos/seriec_245_esp.pdf> (consulta 06/01/2020).

Constitución Política de los Estados Unidos Mexicanos. Texto vigente. Última reforma publicada en el Diario Oficial de la Federación, 08/05/2020, disponible en <http:// www.diputados.gob.mx/LeyesBiblio/pdf/1_080520.pdf> (consulta 11/06/2020). 
Cunningham, Myrma. (2012). A Pillar of Development and Good Living. Culture and Development, 9, pp. 28-39, disponible en: <https://unesdoc.unesco.org/ark:/48223/ pf0000224438_eng?17=null\&queryld=feaa4dc5-1b90-4544-8529-391c098ee8c2> (consulta: 15/06/2020).

Erickson, Kirstin. (2008). Yaqui homeland and Homeplace. The Everyday Production of Ethnic Identity. Tucson, Arizona: The University of Arizona Press.

Feagin, Joe. (2006). Systemic Racism: A Theory of Oppression. New York: Routledge.

Figueroa, Alejandro. (1985). Los que hablan fuerte. Desarrollo de la sociedad yaqui. México: Intituto Nacional de Antropología e Historia/Secretaría de Educación Pública.

Figueroa, Alejandro. (1993). Reproducción cultural e identidad étnica entre los Yaquis y Mayos. Memoria del XVI Simposio de Historia y Antropología, pp. 255-268. México: Universidad de Sonora.

Figueroa, Alejandro. (1994). Por la tierra y por los santos: identidad y persistencia cultural entre Yaquis y Mayos. Hermosillo, México: Consejo Nacional para la Cultura y las Artes/Dirección General de Culturas Populares.

Gomez-Rubio, Paulina, Jason Roberge, Leslie Arendell, Robin B. Harris, Mary K. O'Rourke, Zhao Chen, Ernesto Cantu-Soto, Maria M. Meza-Montenegro, Dean Billheimer, Zhenqiang Lu, Walter T. Klimecki (2011). Association between body mass index and arsenic methylation efficiency in adult women from southwest US and northwest Mexico. Toxicology and Applied Pharmacology, 1(252), pp. 176-182, disponible en: <https://arizona.pure.elsevier.com/en/publications/association-between-body-mass-index-and-arsenic-methylation-effic> (consulta: 12/12/2016).

Gouy-Gilbert, Cécil. (2015). Una resistencia india. Los Yaquis. México: Centro de Estudios Mexicanos y Centroamericanos, 2a ed., [en línea] doi: 10.4000/books.cemca.3352

Grageda, Aarón y Cornerlio Molina. (2013). Lo global como posibilidad de lo étnico. Estrategias de competencia jurídica internacional por el agua, la tierra y el derecho en la comunidad transnacional Yaqui. En Eric Bejarano, Marc Grebe, David Grewe y Nadja Lobensteiner (eds.), Movilizando etnicidad (pp. 225-244). Madrid/Fráncfort: Iberoamericana/Vurvuert.

Guest, James. (2005). Aboriginal Legal Theory and Restorative Justice. En Wanda McCaslin (ed.), Justice as Healing. Indigenous Ways. Writings on Community Peacemaking and Restorative Justice from the Native Law Centre (pp. 337-344). St. Paul, Minnesota: Living Justice Press.

Herrera, José. (2015). The challenge of the cultural diversity in mexico through the official recognition of legal pluralism. Age of Human Rights Journal, 4, pp. 60-80.

Hu-DeHart, Evelyn. (1984). Yaqui resistance and survival: the struggle for land and autonomy, 1821-1910. Madison: University of Wisconsin Press.

Hu-DeHart, Evelyn. (1995). Historia de los pueblos indígenas de México. Adaptación y resistencia en el Yaquimi. Los yaquis durante la Colonia. México: CIESAS/INI.

Lerma, Enriqueta. (2014). Notas para el análisis de la resistencia yaqui en contra del Acueducto Independencia. Sociológica, 29(82), pp. 255-271, disponible en <http:// www.scielo.org.mx/pdf/soc/v29n82/v29n82a8.pdf> (consulta: 01/01/2020). 
Lerma, Enriqueta. (2015). En busca de la autonomía entre los yaquis. Múltiples proyectos de desarrollo y una sola «gran verdad». Revista Pueblos y fronteras digital, 10(19), pp. 285-307, doi: 10.22201/cimsur.18704115e.2015.19.54

Leza, Christina. (2015). The Divided Yoeme (Yaqui) People. Wicazo Sa Review. University of Minnesota Press, 30(2), pp. 5-27, disponible en: <https://www.muse.jhu.edu/ article/603606>.

Leza, Christina. (2018). Indigenous Identities on the U . S . -Mexico Border. Journal of the Southwest, 60(4), pp. 914-936, doi: 10.1353/jsw.2018.0018

McCaslin, Wanda. (2005). Justice as Healing. Indigenous Ways. Writings on Community Peacemaking and Restorative Justice from the Native Law Centre. St. Paul: Living Justice Press.

Meza, Montenegro María, Michael J. Kopplin, Jefferey Burgess y Jay Gandolfi. (2008). Urinary arsenic methylation profile in childres exposed to low arsenic levels through drinking water. Journal of Environmental Toxicological Chemistry, 90(5), pp. 957-970, doi: 10.1080/02772240701782140

Meza, Montenegro Mercedes, Elsa Moreno, María Aldana, María Silveira, Guillermno Rodriguez y Ana Valenzuela (2012). Análisis de piretroides en suelo y agua de zonas agrícolas y urbanas de los valles del Yaqui y Mayo. Pyrethroid analysis in soil and water of agricultural and urban areas of the valleys of Yaqui and Mayo. Revista internacional de contaminación ambiental, 28(4), pp. 303-310.

Million, Dian. (2013). Therapeutic Nations: Healing in an Age of Indigenous Human Rights (pp. 103-122) Arizona: University of Arizona Press.

Moctezuma, José. (2001). De pascolas y venados. Adaptación, cambio y persisntencia de las lenguas yaqui y mayo frente al español. México: Siglo XXI Editores/El Colegio de Sinaloa.

Molina, Cornelio. (2013). Jiak Mamblo, wajori into wa yo'o luturia. El "Proyecto trigo" y la comunidad yaqui en la competencia internacional por la tierra y el agua. Tesis de maestría inédita. México: Universidad de Sonora.

Moreno, José. (2014). Despojo de agua en la cuenca del río Yaqui. México: El Colegio de Sonora.

Olavarría, María. (2003). Crueces, flores y serpientes: simbolismo y vida ritual yaquis. México: Universidad Autónoma Metropolitina/Plaza Valdés.

Organización de las Naciones Unidas (ONU). (2008). La Declaración de Naciones Unidas sobre Derechos de los Pueblos Indígenas. En Resolución aprobada por la Asamblea General de las Naciones Unidas, doi: 10.5354/0718-2279.2008.13508

Organización de las Naciones Unidas (ONU)/Derechos Humanos. (2018). Los derechos de las pueblos indígenas: una mirada desde los organismos del sistema de Naciones Unidas. México: ONU-DH México, disponible en: <https://hchr.org.mx/wp/wp-content/themes/hchr/images/doc_pub/PueblosIndgenas_UnaMirada_2017.pdf> (consulta: 01/01/2019).

Organización Internacional del Trabajo (OIT). (2014). Convenio Núm. 169 de la OlT sobre Pueblos Indígenas y Tribales Declaración de las Naciones Unidas sobre los Derechos de los Pueblos Indígenas. Perú: OIT-Oficina Regional para América Latina y el Caribe, disponible en <https://www.ilo.org/wcmsp5/groups/public/---americas/---ro-lima/ documents/publication/wcms_345065.pdf> (consulta: 01/01/2020). 
Padilla, Esther y Amparo Reyes. (2015). El valle de los yaquis y la colonización "oficial" en un contexto de guerra, 1880-1900. En José Medina y Esther Padilla (coords.), Violencia interétnica en la frontera norte novohispana y mexicana, siglos XVII-XIX. México: El Colegio de Sonora.

Padilla, Raquel. (1995). Yucatán, fin del sueño yaqui: el tráfico de los yaquis y el otro triunvirato. Hermosillo, Sonora, México: Gobierno del Estado de Sonora/Secretaría de Educación y Cultura/Instituto Sonorense de Cultura.

Padilla, Raquel. (2011). Los irredentos parias. Los yaquis, Madero y Pino Suárez en las elecciones de Yucatán, 1911. México: Instituto Nacional de Antropología e Historia.

Padilla, Raquel, Zulema Trejo y Esperanza Donjuan. (2012). Misión, nación y territorio yaquis. En José Felix Gastélum y Raquel Padilla (comp.) Misiones del noroeste de México: origen y destino. México: Fondo Regional para la Cultura y las Artes.

Padilla, Raquel y José Moctezuma. (2017). The Yaquis, a historical struggle for water. Water History, 9(1), pp. 29-43, doi: 10.1007/s12685-017-0194-1

Point, Steven. (2005). Alternative Justice: Testing the Waters. En Wanda McCaslin (ed.), Justice as Healing. Indigenous Ways. Writings on Community Peacemaking and Restorative Justice from the Native Law Centre (pp. 206-211). St. Paul, Minnesota: Living Justice Press.

Radonic, Lucero. (2015). Enviromental Violence, Water Rights, and (Un) Due Process in Northwestern Mexico. Latin American Perspectives, $X X(X X X)$, pp. 1-21, disponible en: <http://www.jstor.org/stable/24574866>.

Rivera, Aracely. (2020). Movilidad étnica transnacional: yaquis en el sur de California. En Héctor Vega (ed.), Globalización y transnacionalismo: perspectivas históricas. Hermosillo, Sonora, México: Universidad de Sonora.

Rivera, Aracely y Aarón Grageda. (2017). Mujeres yaquis por el acceso al agua y a los alimentos. En Aarón Grageda, Héctor Vega, Hirám Félix y Leopoldo García (coords.), Género y estudios familiares en el noroeste de México. Una visión multidisciplinaria (pp. 227-252). Sonora, México: Universidad de Sonora.

Sawatsky, Jarem. (2009). The ethic of traditional communities and the spirit of healing justice: studies from Hollow Water, the lona Community, and Plum Village. Londres/ Filadelfia: Jessica Kingsley Publishers.

Sawatsky, Jarem. (2018). Healing Justice. Stories of wisdom and love. Winnipeg, Manitoba, Canadá: Red Canoe Press.

Schulze, Jeffrey. (2018). Are We Not Foreigners Here?: Indigenous Nationalism in the Twentieth-Century U.S.-Mexico Borderlands. Chapel Hill, Carolina del Norte: The University of North Carolina Press.

Soria, Sofía. (2019). Políticas indigenistas en la Argentina kirchnerista. Íconos Revista de Ciencias Sociales, 23(64), pp. 203-220, doi: 10.17141/iconos.64.2019.3443

Spicer, Edward. (1940a). Pascua. A Yaqui village in Arizona. Tucson, Arizona: The University of Arizona Press.

Spicer, Edward. (1940b). The Yaqui Indians of Arizona. Kiva, 5(6), pp. 21-24, disponible en <https://www.jstor.org/stable/27861805> (consulta: 01/01/2018). 
Spicer, Edward. (1958). Social Structure and Cultural Process in Yaqui Religious Acculturation. American Anthropologist, 60(3), pp. 433-441, disponible en <https:// www.jstor.org/stable/666332> (consulta: 01/01/2018).

Spicer, Edward. (1980). The Yaquis: a cultural history. Tucson, Arizona: University of Arizona Press.

Stavenhagen, Rodolfo. (2003). Informe del Relator Especial sobre la situación de los derechos humanos y las libertades fundamentales de los indígenas, Informe E/CN.4/2004/80/Add.2, disponible en <https://www.acnur.org/fileadmin/ Documentos/BDL/2006/4357.pdf> (consulta: 01/01/2019).

The International Work Group for Indigenous Affairs (IWGIA). (2018). The Indigenous World. Conpenhagen, Denmark: The International Work Group for Indigenous Affairs, disponible en <https://www.iwgia.org/images/documents/indigenous-world/indigenous-world-2018.pdf> (consulta: 01/01/2019).

Tsosie, Rebecca. (2010). Indigenous Women and International Human Rights Law: The Challenges of Colonialism, Cultural Survival, and Self-Determination. UCLA journal of international law and foreign affairs, 187, pp. 187-237, disponible en <https:// www.jstor.org/stable/45302358> (consulta: 01/01/2020).

US National Archives (S./f). The Constitution of the United States: A Transcription, disponible en <https://www.archives.gov> (consulta 11/06/2020).

Valandra, Edward. (2005). Decolonizing "Truth": Restoring More than Justice. En Wanda McCaslin (Ed.), Justice as Healing. Indigenous Ways. Writings on Community Peacemaking and Restorative Justice from the Native Law Centre (pp. 29-53). St. Paul, Minnesota: Living Justice Press.

Van Ness, Daniel. (1996). Restorative Justice and International Human Rights. En Burt Galaway y Joe Hudson (eds.), Restorative Justice: International Perspectives (pp. 17-36).

Vega, Héctor. (2018). Persistence-Resistance as a Form of Victory: Transnational Ethnic Struggle of the Yoeme People. En Fernanda Pattaro, Astelio Silvera, Ignazia Bartholini y Roberta Di Rosa (eds.), Migrations: a global welfare challenge, policies, practices and contemporary vulnerabilities (pp. 125-144). Barranquilla, Colombia: Coruniamericana Corporación Universitaria Americana.

Williams, Robert Jr. (2005). Like a Loaded Weapon: the Rehnquist Court, Indian Rights, and the Legal History of Racism in America. Minnesota: University of Minnesota Press.

Zárate, José. (2016). Grupos étnicos de Sonora: territorios y condiciones actuales de vida y rezago. Región y Sociedad, 28(65), 5-44, doi: 10.22198/rys.2016.65.a356

Zehr, Howard. (2015). The Little Book of Restorative Justice. Nueva York: Good Books/ Skyhorse Publishing.

\section{Cómo citar este artículo:}

Rivera Cohen, Aracely y Elia Castro Peralta (2021), «Justicia restaurativa para la población yaqui de la frontera entre México y Estados Unidos: yaquis del río y yaquis del sur de California». Revista Pueblos y fronteras digital, 16, pp.1-30, doi: 10.22201/cimsur.18704115e.2021.v16.537. 